\title{
Immediate Implant Placement in Anterior Maxilla
}

\author{
Dr. John Gurung, ${ }^{1}$ Dr. Bhageshwar Dhami ${ }^{2}$ \\ ${ }^{1}$ Department of Oral and Maxillofacial Surgery, Kantipur Dental College, Kathmandu, Nepal; \\ ${ }^{2}$ Department of Periodontics, Kantipur Dental College, Kathmandu, Nepal.
}

\begin{abstract}
This case report describes extraction of a fractured right maxillary lateral incisor tooth which was previously treated endodontically, followed by immediate placement of a dental implant in the prepared socket and temporisation by a removable partial denture. The tooth was extracted with minimal hard and soft tissue trauma. The socket was prepared to the required depth and implant was inserted. An impression was made after four months, and a definitive restoration was placed. The atraumatic operating technique and the immediate insertion of the implant resulted in the preservation of the hard and soft tissues at the extraction site. The patient exhibited no clinical or radiologic complications after loading.
\end{abstract}

Keywords: Crown; immediate healing abutment; immediate implant; implant; single stage implant.

\section{INTRODUCTION}

Missing teeth and supporting oral tissues have traditionally been replaced with dentures or bridges allowing functional restoration of mastication, speech, and aesthetics. ${ }^{1}$ Dental implants offer a better alternative. The implants are inserted into the jawbones to support a dental prosthesis and are retained because of osseointegration. ${ }^{2}$ Osseointegration was first described by Branemark (1977), ${ }^{2,3}$ as the direct structural and functional connection between living bone and implant surface. It has definitely been one of the most significant scientific breakthroughs in dentistry. Teeth may have been lost through dental diseases or trauma or they may be congenitally absent. However in many clinical situations compromised teeth or roots may still be present in the patient's mouth. Before the invention of dental implants, compromised teeth were removed and the extraction sockets were left to heal for several months. Conventionally, implants are placed three to six months after the extraction of teeth. However, the majority of patients are interested in shortening the treatment duration between tooth extraction and implant placement or even better in having the implants inserted at the same day (immediate implants) ${ }^{4,5}$ which is well documented. ${ }^{5}$

\section{Correspondence:}

Dr. John Gurung

Deparment of Oral and Maxillofacial Surgery,

Kantipur Dental College, Kathmandu, Nepal.

email: johngrg24@gmail.com

\section{Citation}

Gurung J, Dhami B. Immediate Implant Placement in Anterior Maxilla. J Nepal Soc Perio Oral Implantol. 2018;2(2):70-2

\section{CASE REPORT 1}

A 32 year-old female reported of root stump in upper right front region and gave history of fractured maxillary right lateral incisor due to road traffic accident a week ago in which root canal therapy was done two years ago. She was referred to Department of Periodontics for needful treatment after endodontic evaluation. Patient's general and medical history were taken and was not significant. Patient was examined clinically and cone beam computed tomography was taken. After thorough analysis clinically (Figure 1) and radiographically (Figure 2) it was evaluated that there was no underlying pathology and tooth root was unrestorable. It was there and then decided to do immediate implant placement and so was desired by the patient. Tooth root was extracted atraumatically under local anaesthesia after

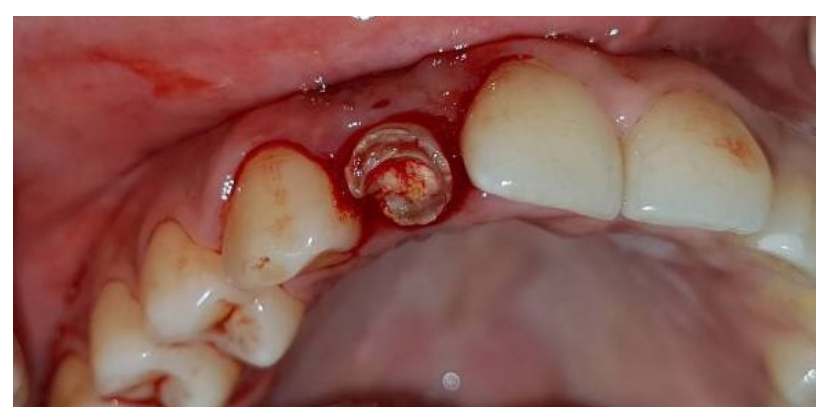

Figure 1: Pre-operative clinical view.
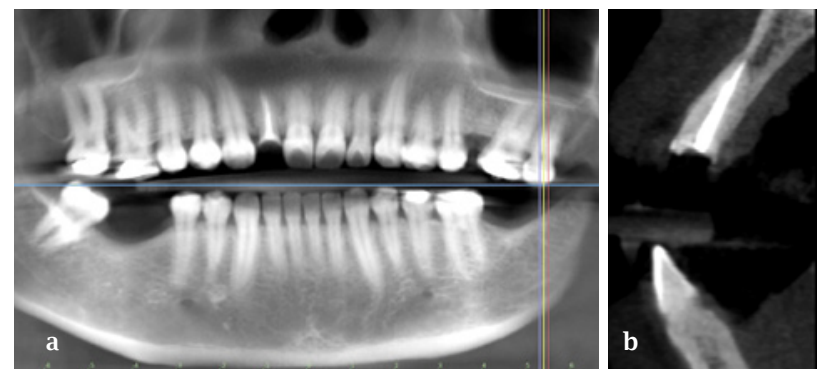

Figure 2: (a) Pre-operative radiographic view (b) Lateral View. 


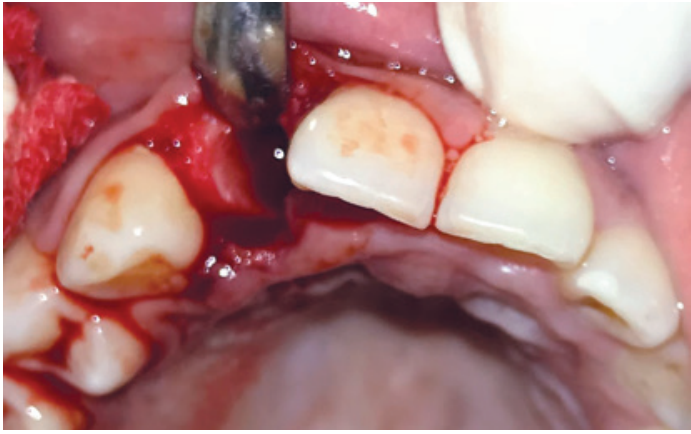

Figure 3: Extraction socket

carefully raising the flap (Figure 3). The pilot drill was used for creating a osteotomy site of the appropriate depth that is $13 \mathrm{~mm}$ for implant placement. When appropriate depth was reached with the pilot drill, the implant depth probe was used for tactile perception of intact bony plates and or any perforations and the confirmation of desired osteotomy depth. Once desired depth was confirmed, 2.0 $\mathrm{mm}$ diameter drill was used and same was used to check the proper alignment of the implant with adjacent teeth and opposing occlusion (Figure 4). After confirmation of depth and angulation, the osteotomy site was prepared for $3 \mathrm{~mm}$ diameter implant. The Implant site was generously irrigated with normal saline to remove any residual bone chips/other residue following preparation. The depth of the osteotomy was ascertained with Implant depth probe. Contamination by touching the implant with instruments made of a dissimilar metal or by contact with soft tissue, cloth or even surgical gloves may affect the degree of osseointegration. The implant (3x13 mm, Dio Implants, South Korea) was removed from the sterile vial using the insertion tool and inserted into the osteotomy site (Figure 5, 6). The torque was around $25 \mathrm{Ncm}$ so it was planned to put the healing abutment

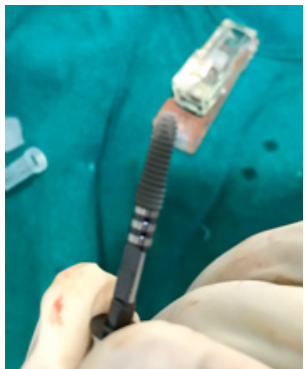

Figure 5: Implant $3 \mathrm{~mm} \times 13 \mathrm{~mm}$.

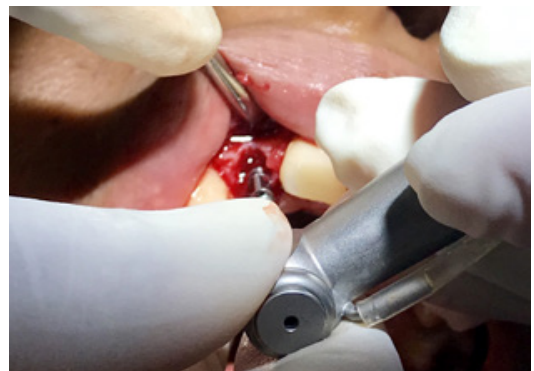

Figure 6: Implant placement.

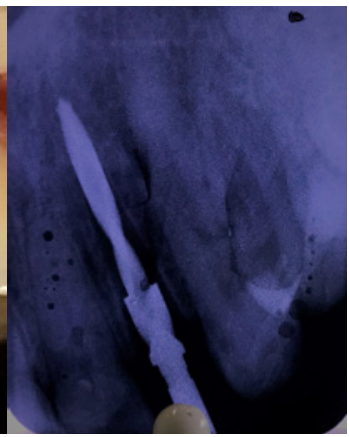

Figure 4: Checking proper alignment

preventing second stage surgery. The flap margins were then repositioned and sutured tension free using 3-0 silk in interrupted fashion (Figure 7). A radiograph was taken post operatively to evaluate the implant angulation and position (Figure 8). Antimicrobials (Capsule Amoxicillin + Clavulanic acid $625 \mathrm{mg}$ TDS for 7 days), Analgesics (Ibuprofen $400 \mathrm{mg}$ + Paracetamol 500 mg TDS for 5 days), and Chlorhexidine mouthwash $0.2 \%$ twice daily for two weeks were prescribed. The patient was on regular recall and under strict oral hygiene measures. The patient was recalled after 16 weeks, radiograph was taken and prosthetic phase was carried out. After soft tissue healing, impressions were made with the impression post attached to the implant using the closed tray impression technique. Shade selection was also done during this appointment. Casts with impression post-implant analogue complex, abutment, lab drivers and selected shade were sent to laboratory for preparation of cement retained Zirconium crown. After one week, the healing abutment was removed and replaced with final abutment (Figure 9). The Zirconium crown was cemented with dual cure composite resin (Figure 10). Oral hygiene instructions were reinforced and recalled for regular follow-ups (Figure 11, 12). clinical view.

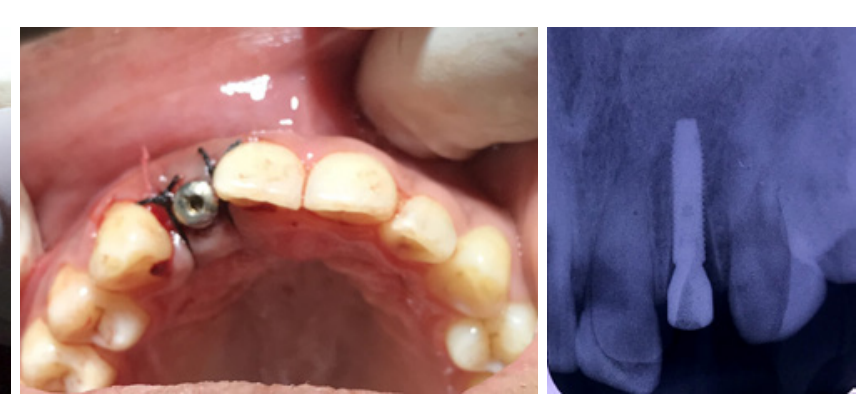

Figure 7: Implant with healing abutment Figure 8: Implant placement radiographic view.

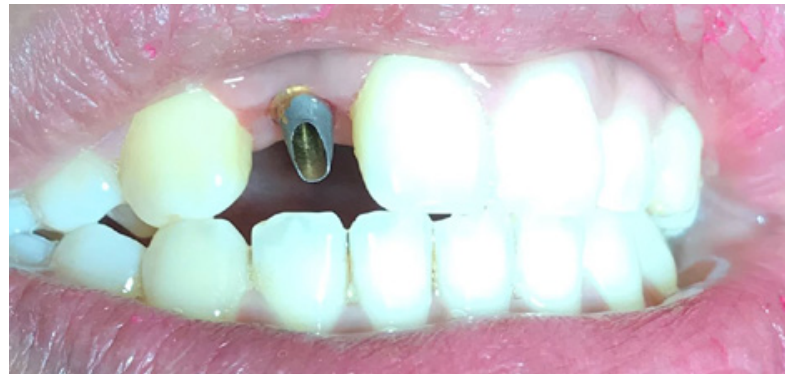

Figure 9: Final abutment placement.

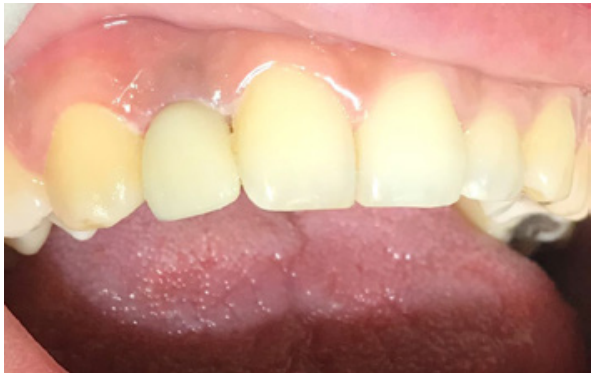

Figure 10: Final crown placement. 

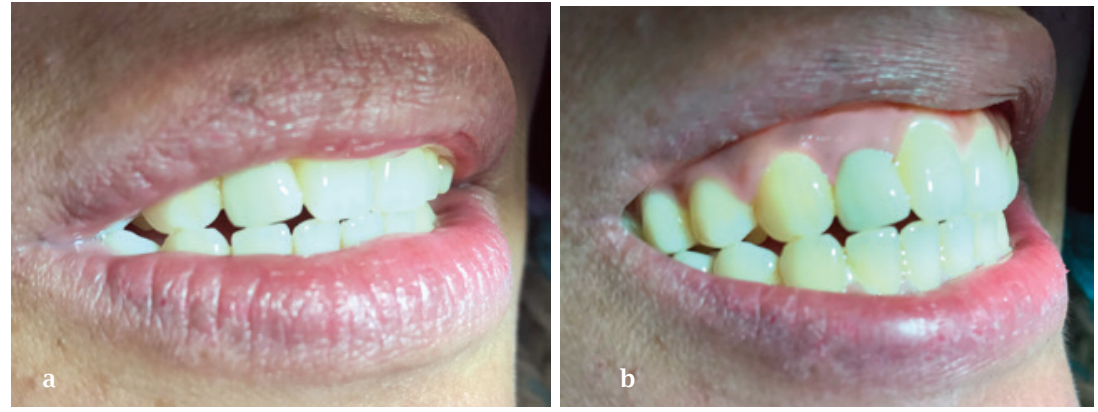

Figure 11: (a,b) One month follow-up.

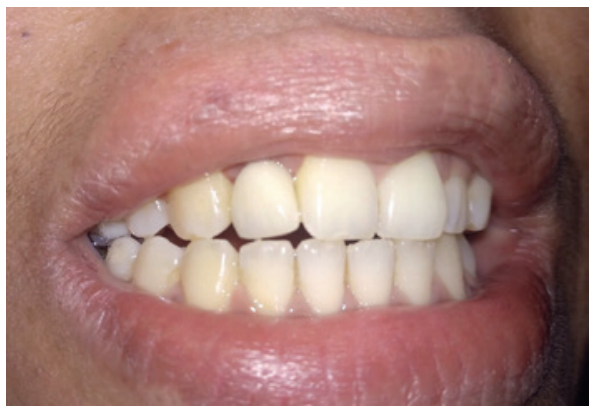

Figure 12: Two months follow-up.

\section{DISCUSSION}

Many clinical reports and experimental studies in the animal model demonstrated the favourable outcomes of dental implants immediately inserted in freshly extraction socket, without the use of any regenerative materials..$^{2,3,5-8}$ These data agree with those from other authors who evaluated the clinical success rate of immediate implantation without use of any membrane or graft material in both humans and animals. ${ }^{9}$ It must be kept in mind that the present study is related to immediate implant not subjected to functional loading and therefore not fully comparable with the results from loaded implants. However, it has been demonstrated that functional loading does not impair, but rather enhance, bone maturation. . $10^{10}$

This case report describes a technique to preserve and augment anterior aesthetics by combining atraumatic teeth extraction, hard and soft tissue augmentation, immediate provisionalisation and using the platform switching concept to preserve the buccal plate. The gingival tissue surrounding the implants has remained stable with no recession. The implant therapy must fulfill both functional and aesthetic requirements to be considered a primary treatment modality.

\section{REFERENCES}

1. Wagenberg BD, Ginsburg TR. Immediate implant placement on removal of the natural tooth: retrospective analysis of 1,081 implants. Comp Cont Educ Dent. 2001;22:399-404.

2. Bajali M, Abdulgani Azz, Abu-Hussein ; Extraction and immediate implant placement, and provisionalization with two years follow-up: a case report. Int J Dent Health Sci. 2014;1(2):229-36.

3. Branemark PI, Hansson BO, Adell R, Breine U, Lindstrom J, Hallen O, et al. Osseointegrated implants in the treatment of the edentulous jaw. Experience from a 10-year period. Scand J Plast Reconstr Surg Suppl. 1977;16:1-132.

4. Douglass GL, Merin RL. The immediate dental implant. J California Dent Assoc. 2002;30:362-5.

5. Abu-Hussein M, Abdulghani A, Sarafianou A, Kontoes N. Implants into fresh extraction site: A literature review,case immediate placement report, J Dent Implants. 2013;3;2:160-4.

6. Esposito M, Grusovin MG, Worthington H, Coulthard P. Intervention for replacing missing teeth: bone augmentation techniques for dental implant treatment. Cochrane Database Syst Rev. 2008;16;(3).

7. Esposito M, Hirsch JM, Lekholm U, Thomsen P. Biological factors contributing to failures of osseointegrated oral implants. (II) Etiopathogenesis. Eur J Oral Sci. 1998;106(3):721-64.

8. Schwartz-Arad D, Chaushu G. Placement of implants into fresh extraction sites:4-7 years' retrospective evaluation of 95 immediate implants. J Periodontol. 1997;68:1110-6.

9. Strub JR, Kohal RJ, Klaus G, Ferraresso F. The reimplant system for immediate implant placement. J Esthet Dent. 1997;9:187-96.

10. Paolantonio M, Dolci M, Scarano A, d'Archivio D, di Placido G,Tumini V,et al. Immediate implantation into fresh extraction sockets. A controlled clinical trial and histological study in man. J Periodontol. 2001;72(11):1560-71. 